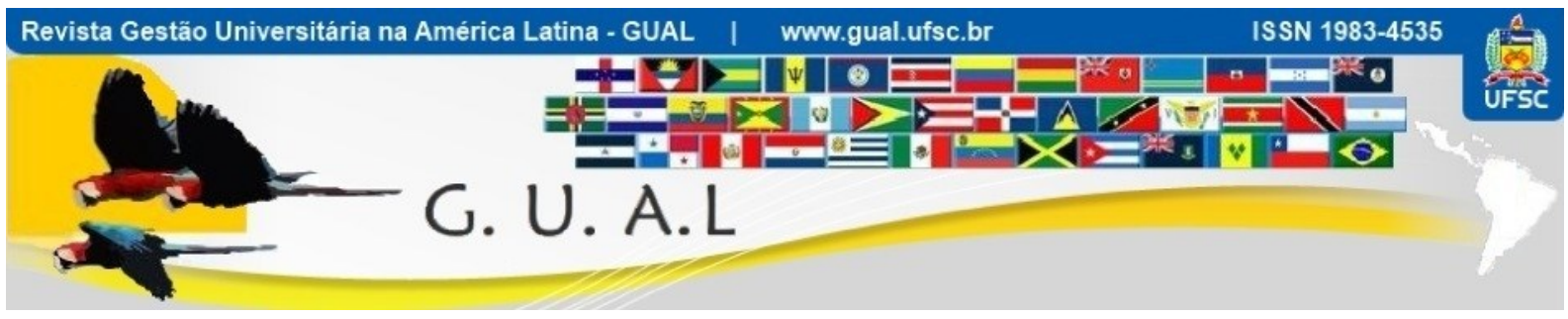

DOI: http://dx.doi.org/10.5007/1983-4535.2012v5n2p277

\title{
A EXECUÇÃO DAS TAREFAS VIRTUAIS NO CONTEXTO DA EDUCAÇÃO A DISTÂNCIA: UM ESTUDO EM UM CURSO DE GRADUAÇÃO EM ADMINISTRAÇÃO
}

\section{EXECUTION OF THE VIRTUAL TASKS IN THE CONTEXT DISTANCE EDUCATION: A STUDY IN AN UNDERGRADUATE COURSE IN ADMINISTRATION}

\author{
Alexandre Costa Quintana, Doutor \\ Universidade Federal do Rio Grande - FURG \\ quintana@vetorial.net \\ Cristiane Gularte Quintana, Mestre \\ Universidade de Caxias do Sul - UCS \\ cristianequintana@hotmail.com
}

Recebido em 21/janeiro/2012

Aprovado em 21/junho/2012

Sistema de Avaliação: Double Blind Review

Esta obra está sob uma Licença Creative Commons Atribuição-Uso. 


\title{
RESUMO
}

O processo de aprendizado virtual passa pela necessidade da existência de um processo de avaliação. Normalmente, essa avaliação é integrada por uma parte virtual e outra presencial. A postagem da tarefa torna-se um importante instrumento de comunicação entre alunos, professores e tutores, pois possibilita a troca de informações entre esses envolvidos, além de servir como componente de avaliação e, por consequência, refletir no desenvolvimento do processo de ensino e aprendizagem. Nesse sentido, o objetivo deste trabalho é analisar a forma de execução das tarefas virtuais do aluno do curso de graduação em Administração a distância. O trabalho foi elaborado por meio de uma pesquisa descritiva, com análise de conteúdo e abordagem qualitativa. Os resultados deste estudo mostram que, no entendimento dos acadêmicos, é fundamental que professores, tutores e coordenação dos cursos a distância prestem atenção às necessidades dos estudantes em relação ao tempo para execução das atividades, data apropriada para postagem e atendimento a dúvidas, essas tarefas se tornam efetivamente um instrumento relevante no processo de ensino e aprendizagem.

Palavras-chave: Educação a distância. Tarefas virtuais. Ensino.

\begin{abstract}
The process of virtual learning passes for the necessity of the existence of an evaluation process. Normally, this evaluation is integrated by a virtual part and another class attendance. The posting of the task becomes an important communication tool between students, teachers and tutors, as it enables the exchange of information between those involved, besides serving as a component of assessment and therefore reflecting the development of teaching-learning process.In this direction the objective of this work is in the distance to analyze the form of execution of the virtual tasks of the pupil of the course of graduation in Administration at distance. This work was elaborated, by means of a descriptive research, with analysis of content and a qualitative boarding. Concluding that the results of this study show that teachers, tutors and coordination of distance courses have attention on the needs of students in relation to time for implementation, appropriate date for posting and service to academics, that in understanding these will be key to the tasks are actually an important tool in the teaching-learning.
\end{abstract}

Keywords: Distance education. Virtual tasks. Learning. 


\section{INTRODUÇÃO}

Atualmente, a educação a distância passa por um momento de forte expansão, configurando este como um período propício para se analisarem as práticas dessa modalidade de ensino, principalmente no que se refere ao nível da graduação.

A internet alterou as maneiras pelas quais professores universitários podem ensinar e os alunos podem aprender. O movimento para o ambiente on-line de ensino e aprendizagem, no entanto, raramente faz parte de uma visão planejada, e as universidades agora estão começando a experimentar o impacto da crescente utilização das tecnologias sobre a política acadêmica (WALLACE, 2007).

Segundo Glen (2005), o aprendizado virtual pode ser descrito como a integração da pedagogia, da tecnologia da informação e da internet para a experiência de ensino e aprendizagem.

Esse processo de aprendizado virtual passa pela necessidade da existência de um processo de avaliação. Normalmente, essa avaliação é composta por uma parte virtual e outra presencial. Neste estudo, procura-se analisar a avaliação virtual, no sentido de identificar quais os fatores que interferem no processo de postagem de tarefas virtuais.

A postagem da tarefa torna-se um importante instrumento de comunicação entre alunos, professores e tutores, pois possibilita a troca de informações entre esses envolvidos, além de servir como componente de avaliação e, por consequência, refletir no desenvolvimento do processo de ensino e aprendizagem.

Nesse sentido, a questão de pesquisa é: como o aluno de graduação executa as tarefas virtuais propostas nas disciplinas do curso a distância?

Para responder à questão de pesquisa, este trabalho analisa a forma de execução das tarefas virtuais do aluno do curso de graduação em Administração a distância da Universidade Federal do Rio Grande - FURG.

O trabalho justifica-se por trazer mais subsídios para os docentes e tutores do ensino a distância, na expectativa de entender os motivos que levam o aluno a não entregar uma tarefa virtual avaliada ou até mesmo a postá-la nos últimos minutos.

\section{FUNDAMENTAÇÃO TEÓRICA}

Os temas abordados no referencial teórico, procurando destacar o sistema operacional utilizado na educação a distância, são a estrutura da Universidade Aberta do Brasil, a 
educação a distância, a tecnologia da informação e comunicação e aspectos da aprendizagem e avaliação.

\subsection{Moodle}

O software utilizado para as atividades relacionadas à educação a distância denominado Moodle (modular object-oriented dynamic learning environment) foi desenvolvido por Martin Dougiamas. Em 1999, foi lançada a sua primeira versão, com uma base pedagógica que, segundo Pulino (2004), tem uma abordagem social construcionista da educação, representando uma grande vantagem sobre outras plataformas. A base conceitual principal do sistema tem por fundamento uma página em que professores disponibilizam informações e propõem atividades para os alunos. Estima-se que o Moodle atualmente encontre-se disponível para mais de 50.000 instituições no mundo - dentre elas, o Ministério da Educação brasileiro (MEC). Essa plataforma armazena diversas informações em um único banco de dados, disposto em grandes grupos, como: configuração, usuários e perfis, tipos de usuários e suas delimitações, cursos, grupos e agrupamentos, $\log s$, eventos, estatística, notas, banco de questões, sistema de mensagens, rede, atividades e blocos (SCHAF, 2011).

De acordo com Graf (2002), uma avaliação realizada em diversas plataformas destinadas ao aprendizado on-line, cujo principal objetivo foi verificar a adaptabilidade dessas plataformas, o sistema Moodle se mostrou superior a outras, também tendo destaque em relação à usabilidade. Foram identificados como pontos fortes do sistema as ferramentas de comunicação e a criação e administração de elementos de aprendizado.

O Moodle, na função de um sistema de gestão de ensino e aprendizagem, apresenta algumas vantagens em relação à participação, comunicação e colaboração entre professores, tutores e alunos. O sistema contribui também para o processo de avaliação, pois são oferecidas ao aluno ferramentas específicas como a possibilidade de discussões de fórum, trabalhos enviados ou realizados on-line, lições com questões, entre outras.

\subsection{Universidade Aberta do Brasil - UAB}

O decreto $\mathrm{n}^{\mathrm{o}} 5.800$, de 8 de junho de 2006, regulamenta o Sistema Universidade Aberta do Brasil, e por meio de seu art. $1^{\circ}$ esse sistema é "voltado para o desenvolvimento da modalidade de educação a distância, com a finalidade de expandir e interiorizar a oferta de 


\section{A EXECUÇ̃̃O DAS TAREFAS VIRTUAIS NO CONTEXTO DA EDUCAÇÃO A DISTÂNCIA: UM \\ ESTUDO EM UM CURSO DE GRADUAÇÃO EM ADMINISTRAÇÃO \\ DOI: http://dx.doi.org/10.5007/1983-4535.2012v5n2p277}

cursos e programas de educação superior no País" (BRASIL, 2006), ou seja, de oportunizar ao acesso ao ensino superior a diversas regiões onde não exista o ensino presencial público.

Nesse sentido, o parágrafo único do art. $1^{\circ}$ do decreto $n^{\circ} 5.800 / 2006$ define como objetivos do Sistema UAB (BRASIL, 2006):

I - oferecer, prioritariamente, cursos de licenciatura e de formação inicial e continuada de professores da educação básica;

II - oferecer cursos superiores para capacitação de dirigentes, gestores e trabalhadores em educação básica dos Estados, do Distrito Federal e dos Municípios;

III - oferecer cursos superiores nas diferentes áreas do conhecimento;

IV - ampliar o acesso à educação superior pública;

$\mathrm{V}$ - reduzir as desigualdades de oferta de ensino superior entre as diferentes regiões do País;

VI - estabelecer amplo sistema nacional de educação superior a distância; e

VII - fomentar o desenvolvimento institucional para a modalidade de educação a distância, bem como a pesquisa em metodologias inovadoras de ensino superior apoiadas em tecnologias de informação e comunicação.

De acordo com o portal eletrônico da CAPES (2010), “o Sistema UAB foi criado pelo Ministério da Educação no ano de 2005, em parceria com a ANDIFES e Empresas Estatais, no âmbito do Fórum das Estatais pela Educação com foco nas Políticas e a Gestão da Educação Superior”. Trata-se de uma política pública que envolve o Ministério da Educação e a CAPES, com a efetiva intenção de expandir a educação superior, no âmbito do Plano de Desenvolvimento da Educação - PDE.

O Sistema UAB sustenta-se em cinco eixos fundamentais: expansão pública da educação superior, considerando os processos de democratização e acesso; aperfeiçoamento dos processos de gestão das instituições de ensino superior, possibilitando sua expansão em consonância com as propostas educacionais dos estados e municípios; avaliação da educação superior a distância tendo por base os processos de flexibilização e regulação implantados pelo MEC; estímulo à investigação em educação superior a distância no País; financiamento dos processos de implantação, execução e formação de recursos humanos em educação superior a distância.

Dessa forma, o Sistema UAB veio com o firme propósito de colocar a educação a distância ao alcance da sociedade em geral. 


\subsection{Educação a distância}

De acordo com Gonzalez (2005), a educação a distância (EAD) foi definida de forma oficial no Brasil pela Lei das Diretrizes e Bases da Educação Nacional (LDB), em 1996, tendo como precursores os cursos por correspondência e os telecursos, juntamente com os recursos técnicos de comunicação mais atuais, como videoconferências, CD-ROMs, DVDs e a própria rede de computadores, que foi a principal impulsionadora desse tipo de ensino, proporcionando uma transformação não apenas tecnológica, mas também social e pedagógica. Para Moore e Kearsley (2007), a evolução da educação a distância está disposta em cinco gerações: a primeira se refere à correspondência; a segunda, à transmissão por rádio e televisão; a terceira geração se refere às universidades abertas; a quarta, às teleconferências; a quinta e última seria a internet/web.

$\mathrm{O}$ art. $1^{\circ}$ do decreto $\mathrm{n}^{\mathrm{o}} 5.622$, de 19 de dezembro de 2005, caracteriza a educação a distância como uma "modalidade educacional na qual a mediação didático-pedagógica nos processos de ensino e aprendizagem ocorre com a utilização de meios e tecnologias de informação e comunicação, com estudantes e professores desenvolvendo atividades educativas em lugares ou tempos diversos" (BRASIL, 2005).

Palloff e Pratt (apud SCHRÖEDER, 2009) afirmam que a EAD, por meio do uso da internet, representa um novo espaço para que os estudantes tenham a possibilidade de explorar o conteúdo dos cursos de forma colaborativa. Assim, estes podem trabalhar cada um a seu tempo e no seu espaço, sem que necessariamente exista uma disponibilidade mútua de um grupo de estudantes para um estudo colaborativo, tampouco que haja a necessidade de uma centralização do conhecimento no professor, que passa a ser um facilitador do conhecimento.

Esse novo espaço de transmissão de conhecimento a distância precisa também de contatos presenciais. Assim, o parágrafo $1^{\circ}$ do art. $1^{\circ}$ do decreto $n^{\circ} 5.622$ (BRASIL, 2005) afirma que a educação a distância deve organizar-se segundo metodologia, gestão e avaliação peculiares, para as quais deverá estar prevista a obrigatoriedade de momentos presenciais para:

I - avaliações de estudantes;

II - estágios obrigatórios, quando previstos na legislação pertinente;

III - defesa de trabalhos de conclusão de curso, quando previstos na legislação pertinente; e

IV - atividades relacionadas a laboratórios de ensino, quando for o caso. 


\section{A EXECUÇÃO DAS TAREFAS VIRTUAIS NO CONTEXTO DA EDUCAÇÃO A DISTÂNCIA: UM ESTUDO EM UM CURSO DE GRADUAÇÃO EM ADMINISTRAÇÃO DOI: http://dx.doi.org/10.5007/1983-4535.2012v5n2p277}

Além disso, a educação a distância proporciona, segundo Schröeder (2009), em termos de memória, que se mantenham registros perenes e de fácil consulta do material produzido pelos professores e pelas interações entre tutores e alunos, resultando na possibilidade de rápido e fácil acesso ao conhecimento construído - um acesso que se dá, muitas vezes, de forma mais acessível do que seria presencialmente.

Conforme Oliveira (2011, p. 19), "é importante observar que a educação a distância não deve ser vista como uma substituição da educação formal, presencial, convencional, e sim, como uma alternativa. A EAD não concorre com a educação convencional: são duas modalidades do mesmo processo". Portanto, a educação a distância nasce como um dos direitos básicos do cidadão, sendo esta uma modalidade que exige do aluno dedicação e organização na realização das suas tarefas; das instituições que ofertam esse tipo de modalidade, exige-se que tenham a preocupação com o material preparado, de modo que seja suficiente para o aluno compreender e assimilar novos conteúdos.

Nesse sentido, além de focarem a interação entre alunos, ou alunos e professores, os ambientes de educação a distância buscam as interações com a tecnologia, componentes computacionais, ferramentas de comunicação e similares (BARAB et al. apud CORNACHIONE JÚNIOR, 2004).

\subsection{Tecnologias da informação e comunicação}

A tecnologia da informação pode ser definida como um conjunto composto por hardware e software e que é utilizado para coletar, processar, armazenar e disseminar informação, de modo a permitir a tomada de decisões. Já as tecnologias da informação e comunicação destacam-se no sentido de apresentar, em um único meio eletrônico de comunicação, a capacidade de suportar todo o tipo de informação possível de se digitalizar, o que inclui documentos de texto, análises financeiras, imagens, áudio e vídeo (SOUSA, 2003; LAUDON; LAUNDON, 2004).

Segundo Fialho et al. (2006), a dependência humana das TICs traduz-se num movimento cultural em que os principais benefícios trazidos são a capacidade de melhorar a qualidade das informações disponibilizadas e a capacidade de melhorar conhecimentos.

De acordo com Rivas (2009) a tecnologia é um agente de mudança assentado na utilização de códigos, simulações, internet e programas por meio da interação humana. A internet exerce uma influência significativa na maneira como as pessoas aprendem, vivem e 
trabalham. Segundo o autor, nota-se que os recursos educacionais estão sendo desenvolvidos e integrados para serem compartilhados em comunidades virtuais de aprendizagem. Isso motiva a ampliação de pesquisas relacionadas à tecnologia aplicada a educação, o que gera novas maneiras de utilização da tecnologia da informação e comunicação como base ao processo de ensino e aprendizagem nos ambientes virtuais. No entanto, Bogdanov (1999) complementa que a tecnologia não gera a aprendizagem por si; é necessário um envolvimento efetivo de todos os participantes do processo.

As tecnologias da informação e comunicação cada vez mais estão conectando e dominando a sociedade em geral. A informação está fixada na memória das pessoas; assim, com o uso da informatização e do desenvolvimento das tecnologias surge a internet como instrumento de informação, mudando a forma como as pessoas buscam o conhecimento (TEIXEIRA, 2011). Para Prevedello (2011), as tecnologias de informação e comunicação estão agregadas como recursos no processo de ensino e aprendizagem. Porém, quando se trata da educação a distância, as TICs não podem ser ignoradas, pois a utilização delas é fundamental para que essa modalidade de ensino se efetive, de maneira a propiciar autonomia e intercâmbio com o aluno.

\subsection{Aprendizado e avaliação}

A ação de cooperação torna-se fundamental no aprendizado. Segundo Argyle (apud LUCHETTA, 2010), cooperar é atuar em conjunto, de forma coordenada, no trabalho ou nas relações sociais, para atingirem-se metas comuns. Assim, a aprendizagem cooperativa acontece quando o processo educativo se desverticaliza, estando o professor não mais em uma posição superior ao aprendente e sim ao seu lado, ensinando, aprendendo, trocando informações com seus interlocutores e desenvolvendo a consciência crítica e a autonomia. A aprendizagem tradicional no processo de ensino e aprendizagem baseia-se no contato face a face entre professor e aluno; na EAD, essa relação se dá na forma aluno-interface na maioria do tempo, o que faz com que a motivação para o aprendizado assuma um relevante papel (PREVEDELLO, 2011).

De acordo com Robbins (2005 p. 37), a definição de aprendizagem é "qualquer mudança relativamente permanente no comportamento que ocorre como resultado de uma experiência". Isso quer dizer que a mudança no comportamento mostra que ocorreu uma aprendizagem e que a aprendizagem envolve uma mudança, ou seja, o aprendizado só 


\section{A EXECUÇÃO DAS TAREFAS VIRTUAIS NO CONTEXTO DA EDUCAÇÃO A DISTÂNCIA: UM \\ ESTUDO EM UM CURSO DE GRADUAÇÃO EM ADMINISTRAÇÃO \\ DOI: http://dx.doi.org/10.5007/1983-4535.2012v5n2p277}

acontece quando há uma mudança de ações nas pessoas. Segundo o autor, existem três teorias de aprendizagem: o condicionamento clássico, segundo o qual, para aprender uma resposta condicionada, é necessário criar um estímulo condicionado e um não condicionado, ou seja, algo acontece e naturalmente as pessoas reagem de uma maneira; o condicionamento operante, em que as pessoas aprendem um procedimento para alcançar algo que desejam ou para impedir algo que não querem; e, por fim, a aprendizagem social, em que as pessoas podem aprender tanto pela observação quanto pela experiência pessoal.

Macedo e Behar (2005, p. 4) destacam que "o sujeito só sente necessidade de compreender o que é interessante para ele. O que não compreende, não faz sentido algum, não significa nada". Por isso, necessita-se de estruturas cognitivas que permitam que o sujeito estabeleça alguma conexão com o novo. Nesse contexto é que o processo educacional deve trabalhar: levando em conta as estruturas já construídas pelo sujeito e dando-lhe o estímulo à curiosidade, para que ocorram transformações.

Schröeder (2009) evidencia que existe a "possibilidade de errar" ou de "aprender com os erros". Por outro lado, é característica do que preconiza o modelo de aprendizagem construtivista, que, segundo Freire (2001), está relacionado ao seguinte contexto:

não existe ensinar sem aprender e com isto eu quero dizer mais do que diria se dissesse que o ato de ensinar exige a existência de quem ensina e de quem aprende. Quero dizer que ensinar e aprender se vão dando de tal maneira que quem ensina aprende, de um lado, porque reconhece um conhecimento antes aprendido e, de outro, porque, observado a maneira como a curiosidade do aluno aprendiz trabalha para apreender o ensinando-se, sem o que não o aprende, o ensinante se ajuda a descobrir incertezas, acertos, equívocos.

Freire (2001) complementa que o aprendizado do ensinante ao ensinar não se dá necessariamente por meio da retificação que o aprendiz lhe faça de erros cometidos. $\mathrm{O}$ aprendizado do ensinante ao ensinar se verifica à medida que o ensinante, humilde, aberto, se ache permanentemente disponível a repensar o pensado, a rever-se em suas posições; à medida que procura envolver-se com a curiosidade dos alunos e dos diferentes caminhos e veredas que ele os faz percorrer.

Assim, com base no exposto percebe-se que essas diversas possibilidades de aprendizado estão em constante processo de aprimoramento, e que podem ganhar caminhos alternativos, por meio do uso das tecnologias de informação e comunicação. 


\section{A EXECUÇÃO DAS TAREFAS VIRTUAIS NO CONTEXTO DA EDUCAÇÃO A DISTÂNCIA: UM ESTUDO EM UM CURSO DE GRADUAÇÃO EM ADMINISTRAÇÃO DOI: http://dx.doi.org/10.5007/1983-4535.2012v5n2p277}

Segundo Macedo e Behar (2005, p. 3), “a aprendizagem não significa aprender porque alguém ensina, mas sim um processo de construção, reconstrução e de tomada de consciência do próprio desenvolvimento por parte do sujeito".

De acordo com Caldeira (2004), o modelo tradicional de avaliação da aprendizagem está muito próximo das teorias tecnicistas e comportamentalistas que ganharam espaço na década de 1960. Estas, por meio da avaliação, procuravam julgar a efetividade do processo de aprendizagem em função dos "comportamentos esperados". Assim, a avaliação da aprendizagem assumiu, durante décadas, a identidade de um instrumento para análise de desempenho final. O autor complementa que é a partir desse modelo que foram desenvolvidas muitas das ferramentas de avaliação dos ambientes digitais de aprendizagem disponíveis na atualidade. A predominância de instrumentos de verificação quantitativa de aprendizagem nesses ambientes reflete, no fundo, a concepção mecanicista de avaliação: testes de múltipla escolha, ferramentas de verificação quantitativa da participação e de acessos etc.

$\mathrm{O}$ art. $4^{\circ}$ do decreto $\mathrm{n}^{\mathrm{o}} 5.622$ estabelece o seguinte (BRASIL, 2005):

A avaliação do desempenho do estudante para fins de promoção, conclusão de estudos e obtenção de diplomas ou certificados dar-se-á no processo, mediante:

I - cumprimento das atividades programadas; e

II - realização de exames presenciais.

$\S 1^{\circ}$ Os exames citados no inciso II serão elaborados pela própria instituição de ensino credenciada, segundo procedimentos e critérios definidos no projeto pedagógico do curso ou programa.

$\S 2^{\circ}$ Os resultados dos exames citados no inciso II deverão prevalecer sobre os demais resultados obtidos em quaisquer outras formas de avaliação a distância.

Segundo Kratochwill (2007), em relação à avaliação, assumem relevância as contribuições de Freire, por trazerem em si a base epistemológica da sociedade da informação, na qual "ninguém educa ninguém, como tampouco ninguém se educa a si mesmo: os homens se educam em comunhão, mediatizados pelo mundo". As transformações que estão ocorrendo na educação evidenciam que os contextos de aprendizagem não comportam simplesmente a figura do professor-transmissor e do estudante-receptor; por isso, a avaliação precisa ser construída a partir de uma concepção mais ampla.

Existem duas concepções de avaliação, com pressupostos teóricos e objetivos pedagógicos completamente diferentes, que coexistem nas práticas e propostas pedagógicas. Os princípios tecnicistas são presentes na organização e estruturação dos sistemas 


\section{A EXECUÇÃO DAS TAREFAS VIRTUAIS NO CONTEXTO DA EDUCAÇÃO A DISTÂNCIA: UM ESTUDO EM UM CURSO DE GRADUAÇÃO EM ADMINISTRAÇÃO DOI: http://dx.doi.org/10.5007/1983-4535.2012v5n2p277}

educacionais baseados em padrões tradicionais de notas, critérios de classificação, aprovação etc. Por outro lado, a avaliação a partir dos pressupostos construtivistas ainda encontra barreiras tanto de ordem teórica como prática (CALDEIRA, 2004).

De acordo com David et al. (2007), a avaliação do processo de ensino e aprendizagem em cursos a distância precisa ser contínua, e deve levar em consideração o lado quantitativo e o qualitativo. A parte quantitativa analisa aspectos mais objetivos, por meio de atividades que usam escalas de valor para quantificar o grau em que os objetivos foram alcançados. As ferramentas disponíveis na maioria dos sistemas virtuais poderão auxiliar o professor na análise desses aspectos, como, por exemplo, a quantidade de acessos, o número de mensagens enviadas aos fóruns e se o aluno postou as atividades no local apropriado. Esses recursos oferecem informações sobre a participação e o cumprimento das tarefas por parte dos alunos, para que o professor possa avaliá-los e acompanhá-los. No aspecto qualitativo, o professor deve observar as atitudes, o senso crítico, o interesse, a autonomia e a cooperação entre os alunos. Como são aspectos subjetivos, sua detecção depende da capacidade analítica do professor ou tutor, pois as ferramentas tecnológicas não são capazes de fazer isso de forma automática. Dessa forma, o professor precisa estar frequentemente observando o comportamento dos alunos.

Para Caldeira (2004, p. 5), “a preocupação em avaliar a participação de alunos em chats e fóruns explicita bem essa questão. Muitos autores chegam a propor categorias para classificar a participação dos alunos, criando até mesmo um coeficiente de participação para avaliar as interações on-line”. Com esse coeficiente chega-se a uma nota final objetiva. A autora complementa que, apesar do progresso tecnológico e da disseminação dos pressupostos construtivistas, grande parte das ações não deixaram de lado o princípio do "verificar e medir", categorizando, classificando e hierarquizando os alunos. Nesse sentido, é importante considerar a avaliação como parte de um processo dinâmico, que influencia mas que ao mesmo tempo é influenciado pelas respostas dos alunos, pela peculiaridade do contexto e do momento.

No aspecto da avaliação, a inserção das tecnologias utilizadas no ensino a distância nas ações presenciais pode trazer mais subsídios para o professor realizar a avaliação, focando alguns aspectos quantitativos, mas principalmente os qualitativos, pois a comunicação digital, em fóruns, chat etc. exige do estudante a necessidade de expressão escrita, e por isso, o 
professor pode observar com mais convicção o envolvimento e o conhecimento desenvolvido pelo estudante durante o transcorrer das atividades realizadas.

\section{METODOLOGIA}

Em termos metodológicos, este trabalho pode ser classificado, quanto aos seus objetivos, como descritivo, pois não manipula os fatos; apenas os observa, registra, analisa e correlaciona, expondo características de um determinado grupo de pessoas ou fenômeno (CERVO; BERVIAN; SILVA, 2007). Neste caso, o grupo pesquisado foram os alunos do curso de graduação a distância em Administração da Universidade Federal do Rio Grande FURG.

O instrumento utilizado para a coleta de dados deste trabalho foi um questionário com questões abertas e fechadas. O questionário foi direcionado às turmas dos polos de Mostardas, São Lourenço do Sul, Santa Vitória do Palmar, São José do Norte e Santo Antônio da Patrulha. Esse instrumento fornece os chamados dados primários, ou seja, que não foram anteriormente coletados.

Os dados primários foram tratados com a técnica de análise de conteúdo. Esta foi utilizada pois, de acordo com Richardson (1985, p. 176), “é particularmente, utilizada para estudar material do tipo qualitativo - ao qual não se podem aplicar técnicas aritméticas". Dessa forma, quanto à abordagem, a pesquisa pode ser definida como qualitativa.

\section{ANÁLISE DE RESULTADOS}

O presente trabalho foi realizado por meio da aplicação de um questionário para os alunos do curso de graduação em Administração da Universidade Federal do Rio Grande FURG, pertencentes ao Sistema Universidade Aberta do Brasil, nos polos de educação a distância da Universidade.

O questionário foi aplicado durante as visitas realizadas aos polos para a aula presencial da disciplina de Administração Financeira.

Os polos de educação a distância que participaram da pesquisa foram os dos municípios de Mostardas, Santo Antônio da Patrulha, São Lourenço do Sul, São José do Norte e Santa Vitória do Palmar. Os polos citados possuem 68 alunos do curso de Administração; destes, 52 responderam ao questionário, com a seguinte distribuição: 
Tabela 1 Distribuição dos participantes por polo

\begin{tabular}{l|c}
\hline \multicolumn{1}{c|}{ Polo } & Número de alunos \\
\hline Mostardas & 9 \\
\hline Santo Antônio da Patrulha & 12 \\
\hline São Lourenço do Sul & 14 \\
\hline São José do Norte & 5 \\
\hline Santa Vitória do Palmar & 12 \\
\hline TOTAL & $\mathbf{5 2}$ \\
\hline
\end{tabular}

Fonte: Elaborada pelos autores.

O questionário era composto por sete questões, que procuravam identificar como as tarefas são desenvolvidas pelos alunos e qual a sua utilidade no processo de ensino e aprendizagem, destacando qual o melhor momento para o desenvolvimento de cada tarefa, quais os fatores que definem o dia de realização da tarefa, quais as melhores datas de execução, bem como local e tempo de realização e melhor data para postagem.

O primeiro questionamento realizado foi relacionado aos fatores que definem o dia em que as tarefas são desenvolvidas. Assim, foram enumerados vários fatores que acabam interferindo na definição do melhor momento para a realização da tarefa, que envolvem questões pessoais, profissionais e até mesmo relacionadas aos conteúdos das disciplinas desenvolvidas em cada período.

A principal finalidade dessa questão era conhecer esses fatores de modo a identificar que tipo de situação afeta de forma mais representativa a realização da tarefa, no sentido de verificar se ações tomadas pelo professor, como, por exemplo, fixar um mesmo dia da semana para postagem, podem repercutir na realização da tarefa.

A tabela a seguir enumera os fatores mais apontados pelos alunos:

Tabela 2 Fatores que definem o dia em que cada tarefa é desenvolvida

\begin{tabular}{l|c}
\hline \multicolumn{1}{c|}{ Fatores } & Número de menções \\
\hline Prazo de entrega & 29 \\
\hline Tempo disponível entre o trabalho e a vida familiar e social & 17 \\
\hline Complexidade da tarefa & 16 \\
\hline Ordem de entrada & 3 \\
\hline Discussão com colegas & 3 \\
\hline Tempo disponível no trabalho & 2 \\
\hline Exigência de cada disciplina & 2 \\
\hline Disponibilidade no final de semana & 2 \\
\hline Volume de leitura & 2 \\
\hline Retorno do tutor sobre as dúvidas & 1 \\
\hline Questão familiar & 1 \\
\hline Conclusão das leituras sugeridas & 1 \\
\hline Necessidade de pesquisa & 1 \\
\hline
\end{tabular}

Fonte: Elaborada pelos autores. 


\section{A EXECUÇÃO DAS TAREFAS VIRTUAIS NO CONTEXTO DA EDUCAÇÃO A DISTÂNCIA: UM ESTUDO EM UM CURSO DE GRADUAÇÃO EM ADMINISTRAÇÃO DOI: http://dx.doi.org/10.5007/1983-4535.2012v5n2p277}

Nessa questão, destacam-se dois pontos relacionados diretamente à disciplina: o prazo estabelecido pelo professor para a entrega e o nível de dificuldade da tarefa. Além disso, outro ponto relevante nesse contexto é de ordem pessoal: a disponibilidade de tempo do aluno, que no caso da educação a distância se reveste de uma particularidade, visto que, mesmo com o estudo a distância, ainda se exige do acadêmico a disponibilidade de tempo; além disso, muitas vezes as relações familiares e profissionais acabam interferindo no rendimento acadêmico e, por consequência, nas tarefas virtuais.

Outro ponto questionado se relaciona à execução da tarefa, perguntando-se se essa execução acontecia no mesmo momento em que o aluno estudava o conteúdo. Essa questão tinha como finalidade verificar se a tarefa é executada no mesmo momento em que o aluno estuda o material disponibilizado na semana ou se a tarefa é executada em outros momentos.

A questão tinha três opções: "sim", "não" e "às vezes", além de contar com um espaço para observações gerais. A tabela 3 demonstra o total de respostas para cada opção e a representação percentual de cada resposta.

Tabela 3 Execução da tarefa / Estudo do conteúdo

\begin{tabular}{c|c|c}
\hline & Respostas & \% \\
\hline Sim & 20 & 38,46 \\
\hline Não & 6 & 11,54 \\
\hline Às vezes & 26 & 50 \\
\hline Total & $\mathbf{5 2}$ & $\mathbf{1 0 0}$ \\
\hline
\end{tabular}

Fonte: Elaborada pelos autores.

Nota-se que $50 \%$ dos alunos marcaram a opção "às vezes", o que indica que a maioria, em alguns momentos, executa a tarefa junto com o estudo do conteúdo e, em outros momentos, não. Nesses casos, os alunos aproveitaram o espaço de observações para descrever os motivos dessa escolha. A seguir, descreve-se a justificativa dos alunos por polo.

No polo de São Lourenço do Sul foram apontadas as seguintes situações: falta de tempo para concluir a atividade; a opção por desenvolver a tarefa de modo gradativo; por opção pessoal, para ler em um momento e realizar a tarefa em outro; e em função da disponibilidade do tutor para tirar dúvidas.

No polo de Santa Vitória do Palmar apareceram as seguintes observações: opção pessoal, para ler em um momento e realizar a tarefa em outro; dificuldade da tarefa; conteúdo prático ou objetivo; extensão da tarefa. 


\section{A EXECUÇÃO DAS TAREFAS VIRTUAIS NO CONTEXTO DA EDUCAÇÃO A DISTÂNCIA: UM ESTUDO EM UM CURSO DE GRADUAÇÃO EM ADMINISTRAÇÃO DOI: http://dx.doi.org/10.5007/1983-4535.2012v5n2p277}

Nos polos de São José do Norte, Mostardas e Santo Antônio da Patrulha ficou destacada a opção pessoal, ou seja, os alunos optam por ler em um momento e realizar a tarefa em outro, mas também foram consideradas a dificuldade da tarefa e o conteúdo extenso.

Em função da particularidade do ensino a distância, a questão seguinte tinha o objetivo de identificar os melhores dias para desenvolver as tarefas. Essa questão torna-se relevante, pois, no momento em que os professores e tutores preparam o cronograma de atendimento aos polos, é importante que as datas de atendimento coincidam com o momento em que o aluno executa a tarefa, para um maior aproveitamento das atividades.

As respostas sofreram variação em função dos polos. No polo de São José do Norte, dos cinco alunos participantes da pesquisa, quatro preferem os dias da semana para executar as tarefas, enquanto um optou pelo final de semana.

No polo de Mostardas a predominância é pelo final de semana: seis alunos indicaram esse período, enquanto três alunos preferem os dias da semana, principalmente entre a segunda e a quarta-feira.

Em Santo Antônio da Patrulha predominam os dias da semana; apenas três alunos indicaram que também utilizam os finais de semana para a execução das tarefas. Os dias da semana mais indicados foram a segunda e a terça-feira. No caso do polo de Santo Antônio da Patrulha, deve-se destacar que os encontros presenciais ocorrem, normalmente, nos finais de semana. Por isso, os dias de semana acabam sendo mais propícios para a execução das tarefas.

O polo de São Lourenço do Sul é o mais variado de todos, pois não existe a predominância de uma resposta. Várias alternativas foram apresentadas, como, por exemplo, as seguintes: segunda e terça; segunda, quarta e sexta; quarta, quinta e sexta; de segunda a sexta; domingo, segunda, terça e quarta, sempre à noite; durante a semana, à noite, e nos finais de semana; apenas finais de semana; todos os dias da semana.

Em Santa Vitória do Palmar houve uma preferência pelos dias da semana. Apenas quatro alunos indicaram o final de semana juntamente aos demais dias da semana. Não há destaque para algum dia da semana, e apenas dois alunos apontaram seu horário preferido após as 22 horas.

$\mathrm{Na}$ questão 4, procurou-se observar onde normalmente as tarefas são realizadas. A questão oferecia quatro alternativas: o polo, o trabalho, a casa do aluno ou outro local específico. 


\section{A EXECUÇÃO DAS TAREFAS VIRTUAIS NO CONTEXTO DA EDUCAÇÃO A DISTÂNCIA: UM ESTUDO EM UM CURSO DE GRADUAÇÃO EM ADMINISTRAÇÃO DOI: http://dx.doi.org/10.5007/1983-4535.2012v5n2p277}

Nas respostas obtidas, $83,33 \%$ indicaram que as tarefas são realizadas em casa, enquanto $10 \%$ informaram que as realizam no polo; o restante desenvolve as tarefas no trabalho ou em outro local.

No sentido de tentar evidenciar quanto tempo, em média, um aluno demora para desenvolver uma tarefa, a questão 5 procura obter essa informação, com base em cinco opções apresentadas no questionário: uma hora, duas horas, entre duas horas e um dia, entre dois dias a três dias e mais de três dias.

Os resultados apontam o período entre duas horas e um dia como o de maior incidência, com um total de 24 alunos, e o período de dois a três dias com 20 respostas, ou seja, a maior parte dos alunos leva até três dias para realizar uma tarefa. Essa resposta vem de encontro ao exposto em questões anteriores, que indicam que, normalmente, o aluno primeiro estuda o conteúdo para depois desenvolver a tarefa.

Na questão seguinte, o objetivo era verificar qual a preferência, em termos de dia da semana para postagem, visto que, normalmente, essa data é definida pelo professor, sem considerar-se a necessidade de cada polo e, principalmente, o desejo do estudante.

Notou-se uma preferência pelas quartas e sextas-feiras, sendo esses dois dias os mais indicados em todos os polos, representando mais de $70 \%$ da escolha dos alunos. A quintafeira também teve destaque nos polos de Santo Antônio da Patrulha, Mostardas e São Lourenço do Sul. Vale observar que nenhum aluno apontou o sábado como um dia interessante para a postagem.

Acredita-se que essa escolha tem relação com a tendência maior de realização das tarefas durante os dias de semana, deixando-se o final de semana para as atividades pessoais. Assim, as tarefas acabam sendo realizadas nos primeiros dias da semana e postadas entre a quarta e a sexta-feira.

A última questão era absolutamente aberta, no sentido de dar ao aluno toda a liberdade de discorrer sobre a relação das tarefas virtuais com o processo de ensino e aprendizagem.

De uma forma geral, a posição dos alunos foi indicando que as tarefas virtuais representam elemento indispensável na educação a distância, proporcionando repercussões significativas no processo de ensino e aprendizagem.

No polo de Santa Vitória do Palmar, foram relatados os seguintes benefícios da execução de tarefas: "acrescentam conhecimento aos poucos, o que torna o aprendizado mais fácil"; "são de extrema importância no processo de ensino-aprendizagem, visto que, é o meio 


\section{A EXECUÇ̃̃O DAS TAREFAS VIRTUAIS NO CONTEXTO DA EDUCAÇÃO A DISTÂNCIA: UM ESTUDO EM UM CURSO DE GRADUAÇÃO EM ADMINISTRAÇÃO \\ DOI: http://dx.doi.org/10.5007/1983-4535.2012v5n2p277}

de reconhecermos os fatos principais do conteúdo, recebendo o feedback do tutor, é possível modificar conceitos equivocados"; "expandem o conhecimento do aluno"; "são fundamentais para complementar o estudo teórico, sendo um meio de interação com professores e tutores"; "auxiliar na condução dos estudos da disciplina”; "é facilitada a assimilação do aprendizado". Por outro lado, também foi descrito que esse processo precisa da colaboração do tutor, pois o retorno deste precisa acontecer no menor tempo possível, esclarecendo-se as dificuldades, de forma a corrigir os erros encontrados na tarefa.

No polo de São Lourenço do Sul, também predomina o entendimento de que as tarefas contribuem para o processo de ensino e aprendizagem, conforme os relatos a seguir:

\footnotetext{
"As tarefas são de suma importância para o entendimento do conteúdo."

"As tarefas são fundamentais para a fixação dos conteúdos."

"Sem dúvida que as tarefas são importantes e, mais ainda no nosso caso, um curso a distância, é uma maneira de ver o que aprendemos realmente."

"Entendo que aprendemos muito em quanto executamos as tarefas, pois é quando surgem as dúvidas."

"As tarefas no geral são boas e estimulam a aprendizagem através de pesquisas."

"As tarefas são o nosso modo de aprendizagem e aprofundamento das disciplinas. As pesquisas são também instrumentos úteis para não ficarmos restritos ao material postado, assim como os estudos de caso, ou casos postados."

"As tarefas são muito importantes para fixação do conteúdo. São as únicas formas de avaliarmos o nosso aprendizado."
}

Em Santo Antônio da Patrulha, as tarefas são destacadas como indispensáveis e como a principal forma para o desenvolvimento do aprendizado. No entanto, existem algumas afirmações que alertam para outros pontos que devem ser observados para que a tarefa proporcione o resultado desejado, como, por exemplo, as seguintes colocações: "acho que o foco das tarefas está muito direcionado para a nota e não para a aprendizagem"; "as tarefas não apresentam muitas vezes 'objetos' concretos de estudo. Assim, atividades mais práticas seriam interessantes"; e "as tarefas devem ser de acordo com o conteúdo disponibilizado e com uma extensão compatível, pois temos outras atividades a realizar. Estas devem preparar o aluno para a avaliação final".

No polo de São José do Norte pode-se evidenciar a afirmação segundo a qual, sobretudo na $\mathrm{EAD}$, as tarefas têm uma importância fundamental para o entendimento do conteúdo disponibilizado, servindo de instrumento para colocarem-se em prática os conteúdos estudados e assim, cometerem-se erros que possam ser corrigidos antes das avaliações. Por fim, ressalta-se o desejo do aluno em atender ao proposto pelo professor, através da seguinte 
afirmativa: "Na minha opinião, as tarefas têm grande relevância sobre o aprendizado, pois podemos analisar se nosso entendimento está de acordo com o esperado por nossos educadores. E se não estamos equivocados quanto ao entendimento do conteúdo".

Da mesma forma, no polo de Mostardas as tarefas são consideradas de extrema importância para o aprendizado, pois elas norteiam o entendimento sobre o conteúdo. Nesse polo, também foi ressaltada a relevância das tarefas para o surgimento de dúvidas que possam ser esclarecidas pelos tutores, pois no ensino a distância, as tarefas são essenciais para que o aluno consiga assimilar o conteúdo, levantando dúvidas e questões sobre a matéria. Por fim, pode-se destacar a seguinte afirmação: "as tarefas são fontes de conhecimento e com toda certeza geram uma base importante para formação".

Essas afirmações foram destacadas neste trabalho para evidenciar que os alunos reconhecem a necessidade das tarefas para o seu bom desempenho, e que estas são fundamentais no processo de ensino e aprendizagem.

\section{CONSIDERAÇÕES FINAIS}

O presente trabalho teve por objetivo analisar a forma de execução das tarefas virtuais do aluno do curso de graduação em Administração a distância, tendo como resultado que a execução das tarefas sofre influência de fatores como o prazo de entrega e a complexidade da tarefa, além da disponibilidade de tempo do estudante. Observou-se também que as tarefas normalmente são executadas em momento diferente do período destinado ao estudo do conteúdo, que os melhores dias para a sua execução são os dias da semana e que a postagem deveria ser realizada nas quartas e sextas-feiras.

Nota-se, também, que, de forma semelhante ao ensino presencial, as tarefas são executadas normalmente em casa, e que a maioria dos alunos entende que elas são fundamentais no processo de ensino e aprendizagem.

Neste trabalho procurou-se evidenciar o entendimento do estudante, ou seja, a opinião dele em relação ao processo. Contudo, é importante que esse tipo de análise seja processada de outras formas; por isso, pode-se propor estudos futuros que comprovem o reflexo da execução das tarefas no desempenho dos alunos, por meio de uma comparação entre o rendimento acadêmico obtido nas tarefas virtuais, comparadas com as avaliações presenciais, e até mesmo a comparação do desempenho do acadêmico do curso a distância com o do curso presencial. 
Por fim, os resultados deste estudo mostram que, se professores, tutores e coordenação dos cursos a distância prestarem atenção às necessidades dos estudantes em relação ao tempo para execução das tarefas, à data apropriada para a sua postagem e ao atendimento aos acadêmicos, as tarefas se tornarão, no entendimento dos alunos, efetivamente um instrumento relevante no processo de ensino e aprendizagem.

\section{REFERÊNCIAS}

BOGDANOV, D. Information \& communication technologies impact on academic curricula. Educational Technology \& Society, v. 1, n. 2, 1999.

BRASIL. Decreto $\mathbf{n}^{0}$ 5.622, de 19 de dezembro de 2005. Regulamenta o art. 80 da Lei $\mathrm{n}^{\mathrm{o}}$ 9.394, de 20 de dezembro de 1996, que estabelece as diretrizes e bases da educação nacional. Brasília, DF. Disponível em: <http://www.planalto.gov.br/ccivil_03/_Ato20042006/2005/Decreto/D5622.htm>. Acesso em: 1 jul. 2011.

Decreto $\mathbf{n}^{0}$ 5.800, de 08 de junho de 2006. Dispõe sobre o Sistema Universidade Aberta do Brasil - UAB. Brasília, DF. Disponível em $<$ http://www.planalto.gov.br/ccivil_03/_Ato2004-2006/2006/Decreto/D5800.htm>. Acesso em: 23 nov. 2011.

CALDEIRA, A. C. M. Avaliação da aprendizagem em meios digitais: novos contextos. XI Congresso Internacional de Educação a Distância. Salvador, 2004. Disponível em: $<$ http://www.abed.org.br/congresso2004/por/htm/033-TC-A4.htm>. Acesso em: 25 ago. 2010.

CAPES - Coordenação de Aperfeiçoamento de Pessoal de Nível Superior. Histórico, 2010. Disponível em:

$<$ http://uab.capes.gov.br/index.php?option=com_content\&view=article\&id=9\&Itemid=21>. Acesso em: 23 nov. 2011.

CERVO, A. L.; BERVIAN, P. A.; SILVA, R. da. Metodologia científica. 6. ed. São Paulo: Pearson Prentice Hall, 2007.

CORNACHIONE JÚNIOR, E. B. Tecnologia da educação e curso de Ciências Contábeis: modelos colaborativos virtuais. 400 f. Tese (Livre-Docência). Faculdade de Economia, Administração e Contabilidade da Universidade de São Paulo - USP. São Paulo, 2004.

DAVID, P. B. D. et al. Avaliação da aprendizagem em educação a distância numa perspectiva sócio-interacionista. In: SIMPÓSIO BRASILEIRO DE INFORMÁTICA NA

EDUCAÇÃO. Anais..., 2007. Disponível em: <http://www.brie.org/pub/index.php/sbie/article/viewFile/568/554>. Acesso em: 15 ago. 2011.

FIALHO F. A. P. et al. Gestão do conhecimento e aprendizagem: as estratégias competitivas da sociedade pós-industrial. Florianópolis: Visual Books, 2006. 
FREIRE, P. Carta de Paulo Freire aos professores. Estudos Avançados, São Paulo, v. 15, n. 42, maio/ago. 2001. Disponível em: <http://www.scielo.br>. Acesso em: 30 set. 2011.

GLEN, S. E-learning in nursing education: lessons learnt? Nurse Education Today, n. 25, v. 6, p. 415-17, 2005.

GONZALES, M. Fundamentos da tutoria em educação a distância. São Paulo: Avercamp, 2005 .

GRAF, S.; LIST, B. An evaluation of open source e-learning platforms stressing adaptation issues. Vienna University of Technology, 2002. Disponível em: $<$ http://www.campussource.de/aktuelles/docs/icalt2005.pdf $>$. Acesso em: 21 ago. 2010.

KRATOCHWILL, S. Educação on-line: perspectivas para a avaliação da aprendizagem na interface fórum. ANPED - Associação Nacional de Pós-Graduação e Pesquisa em Educação, 30. Reunião, GT 16, Caxambu, 2007. Disponível em: <http://www.anped.org.br>. Acesso em: 21 ago. 2011.

LAUDON, K. C.; LAUDON, J. P. Sistemas de informação gerenciais. São Paulo: Prentice Hall, 2004.

LUCHETTA, L. H. Análise da utilização de um ambiente virtual no aperfeiçoamento do professor como educador ambiental. 109 f. Dissertação (Mestrado em Educação) Programa de Mestrado Acadêmico em Educação, Universidade do Vale do Itajaí. Itajaí, 2010.

MACEDO, A. L.; BEHAR, P. A. A concepção do aluno sobre a própria aprendizagem ao utilizar ambientes virtuais. Novas tecnologias na Educação, v. 3, n. 1, maio 2005.

MOORE, M.; KEARSLEY, G. A educação a distância: uma visão integrada. São Paulo: Thomson Learning, 2007.

OLIVEIRA, L. S. Estudo das tecnologias aplicadas à educação a distância. $133 \mathrm{f}$. Dissertação (Mestrado em Ciência da Computação e Matemática computacional). Universidade de São Paulo - USP. São Carlos, 2011.

PREVEDELLO, C. F. Design de interação e motivação nos projetos de interface para objetos de aprendizagem em EAD. 136 f. Dissertação (Mestrado em Design). Programa de Pós-graduação em Design, Universidade Federal do Rio Grande do Sul - UFGRS. Porto Alegre, 2011.

PULINO, F.A.R. Introdução ao Moodle - ambiente de aprendizagem. Departamento de Engenharia Civil e Ambiental. Universidade de Brasília, 2004. Disponível em: $<$ http://www.moodle.uneb.br/file.php?file=/1/modulo01-moodle_1_.pdf $>$. Acesso em: 21 ago. 2010.

RICHARDSON, R. J. Pesquisa social: métodos e técnicas. São Paulo: Atlas, 1985. 
RIVAS T. Objetivos de aprendizagem no contexto das comunidades virtuais autoorganizadas para a produção de software livre e de código aberto. $327 \mathrm{f}$. Tese (Doutorado). Escola de Engenharia de São Carlos, Universidade de São Paulo. São Paulo, 2009.

ROBBINS S. P. Comportamento organizacional. 11 ed. São Paulo: Pearson Prentice Hall, 2005.

SCHAF, F. M. Arquitetura modular para ambientes virtuais de ensino de automação com suporte à realidade mista e colaboração. $162 \mathrm{f}$. Tese (Doutorado em Engenharia) Programa de Pós-Graduação em Engenharia Elétrica, Universidade Federal do Rio Grande do Sul - UFGRS, Porto Alegre, 2011.

SCHRÖEDER, C. da S. Educação a distância e mudança organizacional na Escola de Administração da UFRGS: uma teoria substantiva. $252 \mathrm{f}$. Tese (Doutorado em Administração) - Programa de Pós-Graduação em Administração, Universidade Federal do Rio Grande do Sul- UFRGS. Porto Alegre, 2009.

SOUSA, S. Tecnologias de Informação. 4. ed. Lisboa: FCA-Editora, 2003.

TEIXEIRA, M. do R. F. Redes de conhecimento em ciências e o compartilhamento do conhecimento. 142 f. Tese (Doutorado em Educação em Ciências). Programa de PósGraduação em Educação em Ciências - Universidade Federal do Rio Grande do Sul. Porto Alegre, 2011.

WALLACE, L. Online teaching and university policy: investigating the disconnect. Journal of Distance Education, v. 22, n. 1, p. 87-100, 2007. 